\section{BRAZIULIAN JOURNAL \\ OF MEDICAL AND BIOLOGICAL RESEARCH}

www.bjournal.com.br
ISSN 1414-431X

Volume 45 (12) 1102-1340 December 2012

\section{BIOMIDICAL SCIENCES}

AND

CLINICAL INVESTIGATION

Braz J Med Biol Res, December 2012, Volume 45(12) 1202-1208

doi: $10.1590 / \mathrm{S} 0100-879 X 2012007500168$

The increased but non-predominant expression of Th17- and Th1-specific cytokines in Hashimoto's thyroiditis but not in Graves' disease

Qiu Qin, Ping Liu, Lin Liu, Rong Wang, Ni Yan, Jing Yang, Xuan Wang, Madhu Pandey and Jin-an Zhang

The Brazilian Journal of Medical and Biological Research is partially financed by
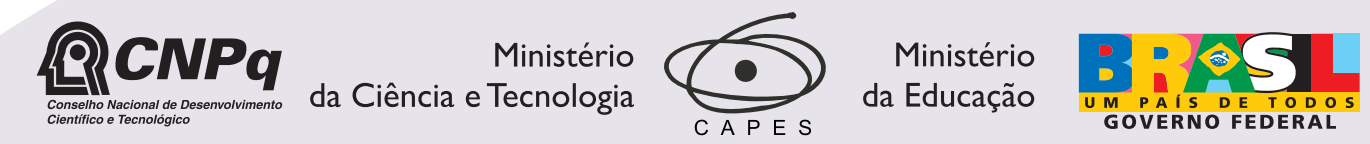

Institutional Sponsors
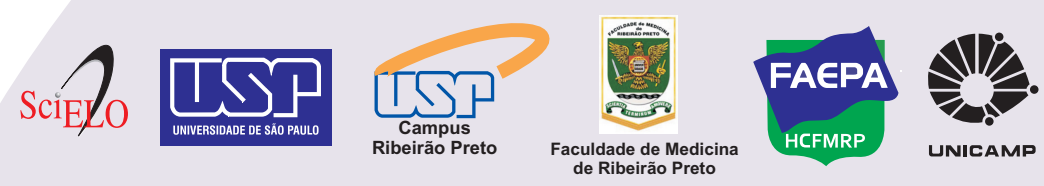

UNICAMP $\oplus$

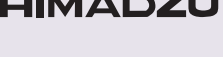

shimadzu 


\title{
The increased but non-predominant expression of Th17- and Th1-specific cytokines in Hashimoto's thyroiditis but not in Graves' disease
}

\author{
Qiu Qin¹, Ping Liu², Lin Liu, Rong Wang ${ }^{1}$, Ni Yan¹, Jing Yang1 ${ }^{1}$ Xuan Wang ${ }^{1}$, \\ Madhu Pandey ${ }^{1}$ and Jin-an Zhang ${ }^{3}$ \\ ${ }^{1}$ Clinical Research Center, First Affiliated Hospital, Medical School, Xi'an Jiaotong University, Xi'an, China \\ 2Department of Endocrinology, Xi'an Central Hospital, Xi'an, China \\ ${ }^{3}$ Department of Endocrinology, Jinshan Hospital, Fudan University, Shanghai, China
}

\begin{abstract}
Hashimoto's thyroiditis (HT) is considered to be mediated mainly by Th1 cells, but it is not known whether Graves' disease (GD) is associated with Th1 or Th2 predominance. Th17 cells, a novel subset of Th cells, play a crucial role in the pathogenesis of various autoimmune disorders. In the present study, the expression of IL-17A and IFN- $y$ was investigated in patients with HT or GD. mRNA expression of IL-17A and IFN- $\gamma$ in peripheral blood mononuclear cells (PBMC) from 43 patients with autoimmune thyroid disease (AITD) and in thyroid tissues from 40 AITD patients were measured by real-time quantitative PCR. The protein expression of IL-17A and IL-23p19 was examined by immunohistochemistry in thyroid tissues from 28 AITD patients. The mRNA levels of IL-17A and IFN- $\gamma$ were higher in both PBMC and thyroid tissues of HT patients than in controls (mRNA levels are reported as the cytokine/ $\beta$-actin ratio: IL-17 $=13.58$ - and 2.88 -fold change and IFN- $\gamma=16.54-$ and 2.74 -fold change, respectively, $\mathrm{P}<0.05)$. Also, the mRNA levels of IL-17A and IFN-y did not differ significantly in GD patients $(P>0.05)$. The high protein expression of IL-17A (IOD = 15.17 \pm 4.8$)$ and IL-23p19 (IOD = 16.84 \pm 7.87$)$ in HT was confirmed by immunohistochemistry $(\mathrm{P}<0.05)$. The similar high levels of IL-17A and IFN-Y suggest a mixed response of Th17 and Th1 in HT, where both cells may play important roles in the destruction procedure by cell-mediated cytotoxicity.
\end{abstract}

Key words: Graves' disease; Hashimoto's thyroiditis; Interleukin-17; Interferon-ү

\section{Introduction}

Autoimmune thyroid diseases (AITD), characterized by autoantibody production and lymphocyte infiltration that usually result in tissue inflammation and cell destruction, mainly comprise Graves' disease (GD) and Hashimoto's thyroiditis (HT). Because of the irregular dietary supply of iodine, the incidence of these diseases has been increasing worldwide in recent years (1). The pathogenesis of AITD is still unclear and both environmental and genetic factors tend to play critical roles. However, the exact roles of these factors, e.g., the roles of cytokines, are still far from clear. At present, more studies focus on the cytokines associated with the abnormal immune response and inflammatory process of these diseases.

CD4+ T helper (Th) lymphocytes are traditionally clas- sified into Th1 and Th2 subsets on the basis of different cytokine secretion. Most studies have found a significantly higher expression of interferon-gamma (IFN-y) (a typical type I cytokine) in $\mathrm{HT}$, suggesting that the cytokine profile in HT has a Th1 bias (2-4). This finding is consistent with other autoimmune inflammatory diseases such as rheumatoid arthritis (RA) and multiple sclerosis (MS). However, animal models of collagen-induced arthritis and experimental autoimmune encephalomyelitis have shown that knockout of the IFN-y gene or the absence of IFN-y signal/receptors in vivo does not provide protection from autoimmune diseases, but rather promotes it (5). These conflicting results strongly suggest the possibility of the participation of another T-cell subset in the development of these autoimmune diseases.

Correspondence: Jin-an Zhang, Department of Endocrinology, Jinshan Hospital, Fudan University, 1508 Longhang Road, Shanghai 201508, China. E-mail: zhangjinan@hotmail.com

Received April 2, 2012. Accepted August 28, 2012. Available online October 26, 2012. Published December 17, 2012. 
Recent studies have identified this new subset of Th cell as "Th17" cell (6-9). Several studies have suggested that Th2-mediated abnormal humoral immunity is closely related to the onset of $G D$, although which cell type is predominant in GD remains controversial (10-12).

Th17 is a novel subset of CD4+ Th lymphocytes that have been recently proposed. Distinct from Th1 and Th2, Th17 cells particularly secrete IL-17, and IL-23 is required for the maintenance of committed Th17 phenotype (13). The expression of Th17 cell-associated cytokines is significantly higher in a number of autoimmune diseases including MS, RA, inflammatory bowel diseases, systemic lupus erythematosus, and psoriasis (14-19). Therefore, we hypothesized that the IL-17/IL-23 axis may also be involved in the pathogenesis of AITD. In the present study, different cytokine levels were measured and the pathogenic cell types occurring in AITD were identified.

\section{Material and Methods}

\section{Blood and tissue samples}

AITD patients were diagnosed according to the clinical diagnostic criteria of AITD, supplemented with the biochemical tests of thyroid function, thyroid ultrasound, and histological examination (20). All the patients in the GD group had hyperthyroidism, goiter and positive thyroid-stimulating hormone receptor antibody (TRAb) and the patients in the HT group showed a high titer of thyroid peroxidases antibody, goiter and negative TRAb. No patient had ever received antithyroid drugs or thyroxine replacement, or had complications of other autoimmune diseases or allergic diseases. The controls had euthyroidism without goiter and showed the absence of antibodies against thyroid components and no other autoimmune diseases. TRAb was measured by radioreceptor assay (Union Medical and Pharmaceutical Technology Limited Company, China). The study was approved by the Clinical Research Ethics Committee of the
First Affiliated Hospital, Xi'an Jiaotong University, and all specimens were collected with written informed consent from the participants.

Real-time quantitative polymerase chain reaction ( $q R T$ $P C R$ ) assay. Blood samples from 27 patients with GD (4 males and 23 females; mean age $=36 \pm 13$ years; range = 15-70 years) and 16 patients with $\mathrm{HT}$ (all females; mean age $=34 \pm 11$ years; range $=19-54$ years) were collected in the outpatient setting of our hospital. Blood samples from 15 healthy individuals matched for age and gender were collected at the Physical Checkup Center of our hospital and used as controls (Table 1). All thyroid tissues were obtained by biopsy from patients with GD or HT. A total of $20 \mathrm{GD}$ samples ( 3 males and 17 females; mean age $=37 \pm 14$ years; range $=17-68$ years $)$ and $20 \mathrm{HT}$ tissues ( 1 male and 19 females; mean age $=42 \pm 9$ years; range $=29-56$ years ) were collected. Fifteen age- and gender-matched normal tissues adjacent to the tumor areas of thyroid adenomas were removed surgically as controls. Clinical information about these samples is shown in Table 2.

Immunohistochemistry assay. A total of $17 \mathrm{HT}$ samples ( 1 male and 16 females; mean age $=38 \pm 11$ years; range = 21-55 years), 11 GD samples (3 males and 8 females; mean age $=36 \pm 6$ years; range $=25-54$ years $), 5$ age- and gender-matched normal tissues ( 1 male and 4 females; mean age $=45 \pm 9$ years; range $=35-57$ years) were processed. Clinical information about these samples is shown in Table 3.

Lymphocytes were extracted from peripheral venous blood and stored at $-80^{\circ} \mathrm{C}$ until assayed. Thyroid tissues were stored in liquid nitrogen.

\section{qRT-PCR}

Peripheral blood monocytes (PBMCs) were separated using Lymphoprep density gradient centrifugation (TianGen Biotech, China). Total RNA from PBMCs and thyroid tissues was extracted with the Trizol reagent (TianGen Biotech)

Table 1. Clinical features of patients with autoimmune thyroid disease whose PBMCs were studied by real-time quantitative PCR.

\begin{tabular}{lcccc}
\hline & Graves' disease & Hashimoto's thyroiditis & Control & Range \\
\hline $\mathrm{N}$ & 27 & 16 & 15 & \\
Gender $(\mathrm{M} / \mathrm{F})$ & $4 / 23$ & $0 / 16$ & $3 / 12$ & \\
Age (years) & $35.6 \pm 12.9$ & $34.4 \pm 10.8$ & $33.8 \pm 7.7$ & \\
Free T4 $(\mathrm{pM})$ & $42.7 \pm 24.16$ & $12.36 \pm 5.35$ & $14.67 \pm 5.5$ & $9.05-25.5$ \\
Free T3 $(\mathrm{pM})$ & $20.1 \pm 12.82$ & $5.8 \pm 3.37$ & $5.79 \pm 2.29$ & $2.91-9.08$ \\
TSH $(\mu \mathrm{lU} / \mathrm{mL})$ & $0.12 \pm 0.05$ & $14.02 \pm 8.44$ & $2.82 \pm 1.2$ & $0.25-5$ \\
TGAb $(\%)$ & $53.59 \pm 74.77$ & $48.64 \pm 19.13$ & Negative & $<30$ \\
TPOAb $(\mathrm{U} / \mathrm{mL})$ & $131.18 \pm 146.6$ & $2459.48 \pm 1038.83$ & Negative & $0-34$ \\
\hline
\end{tabular}

Data are reported as means \pm SD. PBMCs = peripheral blood mononuclear cells; TSH $=$ thyroid-stimulating hormone; TGAb = thyroglobulin antibody; TPOAb = thyroid peroxidases antibody. 
according to manufacturer instructions. For each sample, cDNA was synthesized using $1 \mu \mathrm{g}$ total RNA in $20 \mu \mathrm{L}$ total reaction volume with oligo dT primer, random 6 mers and primescript RT enzyme mix 1 (Primescript RT reagent kit, TaKaRa, China). The PCR amplification of cDNA was performed with SYBR Premix Ex Taq II (Primescript RT reagent kit) in the presence of primers specific for IL-17A (5'-CAA TCC CAC GAA ATC CAG GAT G-3' and 5'-GGT GGA GAT TCC AAG GTG AGG-3'), IFN-Y (5'-GAA GAA TTG GAA AGA GGA GAG-3' and 5'-TGG ATG CTC TGG TCA TCT TT-3'), and $\beta$-actin (5'-ACC CCAAGG CCAACC G-3' and 5'-ACA GCC TGG ATA GCA ACG TAC A-3'). A thermal cycler (Bio-Rad 750, USA) was used to amplify IL-17A, IFN- $\gamma$ and $\beta$-actin. PCR was performed at $95^{\circ} \mathrm{C}$ for $30 \mathrm{~s}$, followed by 35 cycles of denaturation at $95^{\circ} \mathrm{C}$ for 5 $\mathrm{s}$, and annealing at $58^{\circ} \mathrm{C}$ for $30 \mathrm{~s}$. Five microliters of PCR products was examined on $2 \%$ agarose gel and visualized with ethidium bromide. The fluorescence signals were analyzed using the IQ5 software.

\section{Immunohistochemistry}

Samples were fixed in $4 \%$ paraform, dehydrated with an ethanol gradient, and embedded in paraffin. Sections $(4 \mu \mathrm{m})$ were prepared after deparaffination with dimethyl benzene and dehydration with an ethanol gradient. After washing with PBS, the sections were soaked in $0.3 \%$ Triton-X for $40 \mathrm{~min}$ to permeabilize the cell membrane or the nuclear membrane and then treated with $3 \%$ dioxogen to prevent the activity of endogenous peroxidase. Before staining, non-specific binding was blocked with $10 \%$ goat serum at $37^{\circ} \mathrm{C}$ for $10 \mathrm{~min}$ and then at $4^{\circ} \mathrm{C}$ for $48 \mathrm{~h}$ in a humidified chamber. Sections incubated with PBS served as negative controls, and nasal polyp tissues were used as positive staining controls. After incubation with the primary antibody (IL-17A and IL-23p19, diluted 1:50 in PBS) (Biolegend Company, USA), sections were treated with horseradish peroxidase-labeled strepto-antibiotin (diluted 1:200 in PBS; Biosynthesis Biotechnology, China) at $37^{\circ} \mathrm{C}$ for $40 \mathrm{~min}$. Finally, after DAB (ZSGB-Bio, China) staining,

Table 2. Clinical features of patients with thyroid disease whose thyroid tissue was studied by real-time quantitative PCR.

\begin{tabular}{lcccc}
\hline & Graves' disease & Hashimoto's thyroiditis & Control & Range \\
\hline $\mathrm{N}$ & 20 & 20 & 15 & \\
Gender $(\mathrm{M} / \mathrm{F})$ & $3 / 17$ & $1 / 19$ & $2 / 13$ & \\
Age (years) & $37.4 \pm 13.5$ & $41.7 \pm 9.4$ & $41.5 \pm 7.4$ & \\
Free T4 $(\mathrm{pM})$ & $61.04 \pm 57.76$ & $11.95 \pm 3.13$ & $14.98 \pm 5.36$ & $9.05-25.5$ \\
Free T3 $(\mathrm{pM})$ & $26.53 \pm 21.15$ & $4.37 \pm 1.4$ & $5.2 \pm 2.3$ & $2.91-9.08$ \\
TSH $(\mu / \mathrm{U} / \mathrm{mL})$ & $0.17 \pm 0.09$ & $20.67 \pm 29.32$ & $2.63 \pm 1.51$ & $0.25-5$ \\
TGAb $(\%)$ & $35.36 \pm 16.66$ & $30.86 \pm 8.44$ & Negative & $<30$ \\
TPOAb $(\mathrm{U} / \mathrm{mL})$ & $117.4 \pm 75.88$ & $2640.05 \pm 879.26$ & Negative & $0-34$ \\
\hline
\end{tabular}

Data are reported as means $\pm \mathrm{SD}$. TSH = thyroid-stimulating hormone; TGAb = thyroglobulin antibody; TPOAb $=$ thyroid peroxidases antibody.

Table 3. Clinical features of patients with autoimmune thyroid disease whose thyroid tissues were studied by immunohistochemistry.

\begin{tabular}{lcccc}
\hline & Graves' disease & Hashimoto's thyroiditis & Control & Range \\
\hline $\mathrm{N}$ & 11 & 17 & 5 & \\
Gender $(\mathrm{M} / \mathrm{F})$ & $3 / 8$ & $1 / 16$ & $1 / 4$ & \\
Age $($ years $)$ & $36.23 \pm 6.17$ & $38.12 \pm 10.59$ & $45 \pm 9.27$ & \\
Free T4 $(\mathrm{pM})$ & $40.09 \pm 22.13$ & $12.6 \pm 3.54$ & $14.36 \pm 5.93$ & $9.05-25.5$ \\
Free T3 $(\mathrm{pM})$ & $19.78 \pm 11.64$ & $4.65 \pm 1.57$ & $5.42 \pm 2.7$ & $2.91-9.08$ \\
TSH $(\mu \mathrm{lU} / \mathrm{mL})$ & $0.1 \pm 0.04$ & $15.96 \pm 24.69$ & $2.32 \pm 1.36$ & $0.25-5$ \\
TGAb $(\%)$ & $52.76 \pm 70.69$ & $35.54 \pm 15.44$ & Negative & $<30$ \\
TPOAb $(\mathrm{U} / \mathrm{mL})$ & $129.84 \pm 135.42$ & $2717.71 \pm 797.08$ & Negative & $0-34$ \\
\hline
\end{tabular}

Data are reported as means $\pm \mathrm{SD}$. TSH = thyroid-stimulating hormone; TGAb = thyroglobulin antibody; TPOAb = thyroid peroxidases antibody. 
positive cells were observed under the microscope and were counted by the integral optical density (IOD) method by two independent persons.

\section{Statistical analysis}

Data are reported as means \pm SD. The means of multiple samples were analyzed by the Mann-Whitney U-test, and the interclass comparison was tested by the $t$-test or the Mann-Whitney test for independent samples. The paired sample $t$-test and the Wilcoxon rank sum test were used to compare cytokines secreted by Th1 and Th17 cells. A difference with a probability of $P<0.05$ was considered to be significant.

\section{Results}

\section{IL-17A and IFN-y mRNA levels in PBMC and thyroid tissues from AITD patients}

$\mathrm{IL}-17 \mathrm{~A}$ and IFN- $\gamma$ mRNA levels were higher in the peripheral blood of patients with HT compared to healthy controls $(P<0.05$; Figures $1 A$ and 2$)$. The mRNA levels of IL-17A and IFN- $\gamma$ were higher in patients with GD than in normal controls, but the difference was not significant $(P$
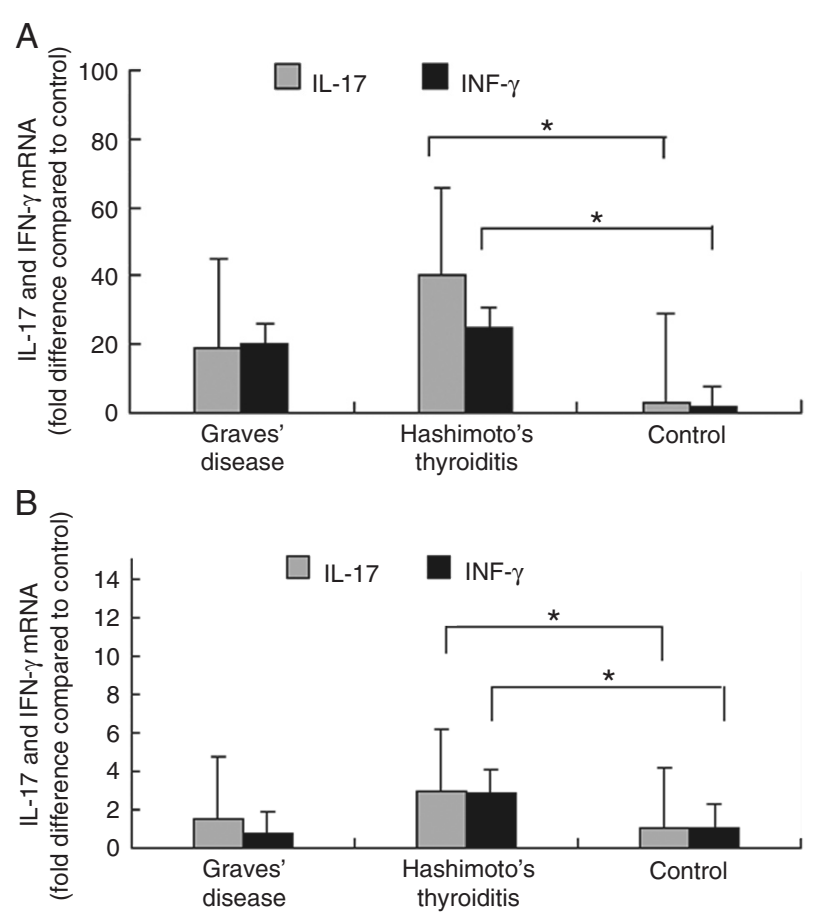

Figure 1. Relative expression of IL-17A and IFN- $y$ mRNA in PBMCs and thyroid tissues. A, IL-17A and IFN-y mRNA expression in peripheral blood from AITD patients and controls. $B$, IL17A and IFN-y mRNA expression in thyroid tissues from AITD patients and controls. PBMCs $=$ peripheral blood mononuclear cells; AITD = autoimmune thyroid disease; ${ }^{*} \mathrm{P}<0.05$ compared to control (the interclass comparison was tested by the $t$-test or the Mann-Whitney test for independent samples).
$>0.05$; Figure 1A).

IL-17A and IFN- $y$ mRNA levels were significantly higher in thyroid tissues from patients with $\mathrm{HT}$ than from healthy controls $(P<0.01)$. For patients with $G D$, IL-17A was higher than normal controls, but the difference was not significant $(P>0.05)$. IFN-y mRNA levels in thyroid tissues from patients with GD showed no significant difference from normal controls ( $P>0.05$; Figure 1B). In addition, the data indicated no significant correlation between mRNA levels of IL-17A and IFN- $y$ in diseased HT lesions ( $P$ > 0.05).

\section{IL-17A and IL-23 protein levels in thyroid tissues from HT patients}

Immunohistochemical analysis revealed higher expression levels of IL-17A and IL-23p19 proteins in HT patients compared to normal controls $(P<0.05)$. The IOD of positive cells in each group is presented in Table 4. The expression of IL-17A and IL-23p19 proteins was detected both in the lymphocyte-infiltrated thyroid tissues and in the follicular epithelial thyroid cells. In contrast, the normal thyroid tissues and tissues from patients with GD only showed slight expression of IL-17A or IL-23p19 (Figure 3).

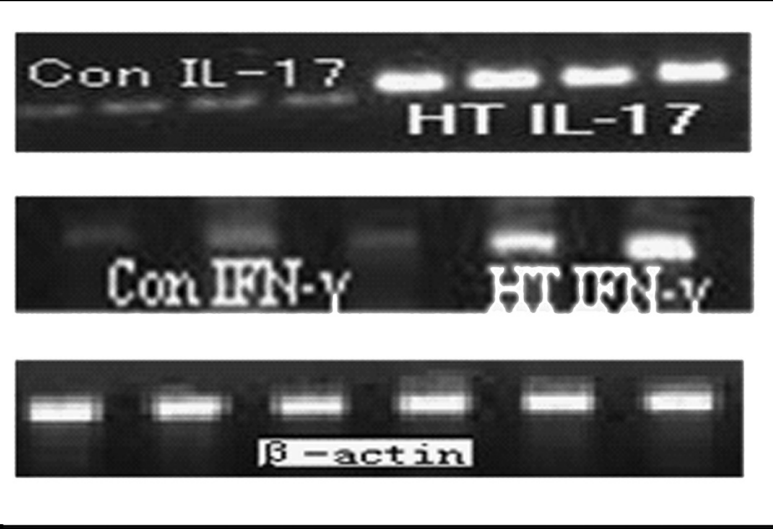

Figure 2. Increased amounts of IL-17A and IFN- $y$ mRNA in HT patients detected by qRT-PCR was shown by gel electrophoresis. $\mathrm{HT}=$ Hashimoto's thyroiditis; Con = control. IL-17 = $156 \mathrm{bp}$; IFN- $\mathrm{Y}=102 \mathrm{bp}$.

Table 4. Protein expression was measured by immunohistochemistry.

\begin{tabular}{lcc}
\hline & $\begin{array}{c}\text { Positive IOD } \\
\text { of IL-17A protein }\end{array}$ & $\begin{array}{c}\text { Positive IOD } \\
\text { of IL-23p19 protein }\end{array}$ \\
\hline Hashimoto's thyroiditis & $15.17 \pm 4.8$ & $16.84 \pm 7.87$ \\
Graves' disease & $3.01 \pm 0.62$ & $3.8 \pm 1.01$ \\
Control & $2.78 \pm 0.92$ & $3.46 \pm 0.99$ \\
\hline
\end{tabular}

Data are reported as means $\pm S D$. IOD = integral optical density. 


\section{Discussion}

AITD are some of the most common organ-specific autoimmune diseases with unknown mechanisms. Although two major types of AITD, GD and HD, have similar genetic backgrounds and pathological processes, they still present significant differences. HT is characterized by the destruction of thyroid cells and the tendency to hypothyroidism. The infiltration of a large number of lymphocytes is the most
IL-17A
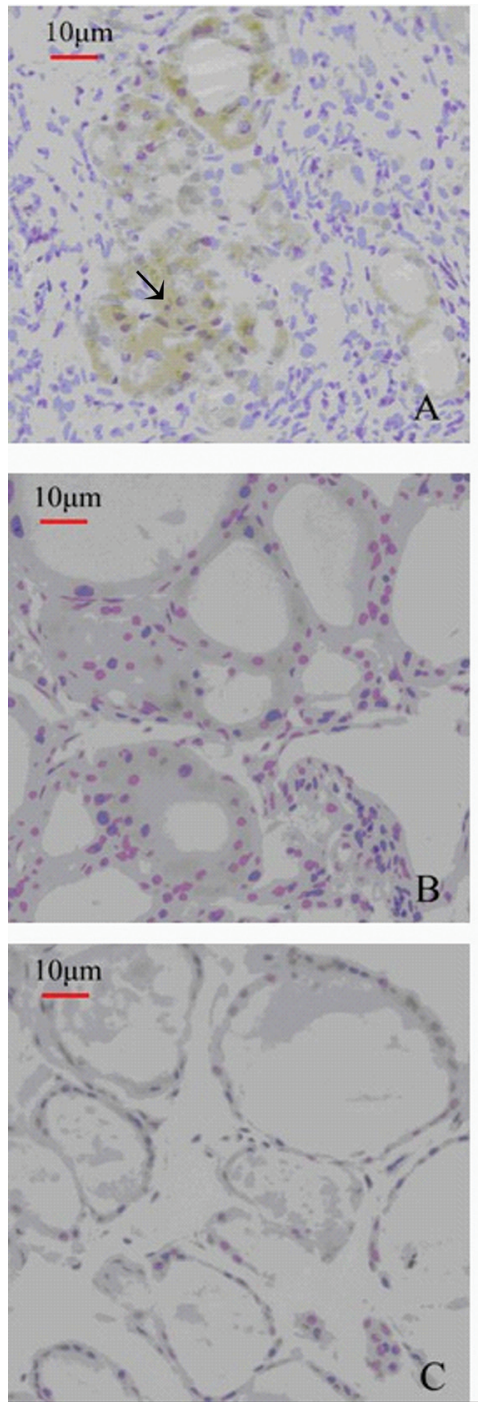

IL-23p19
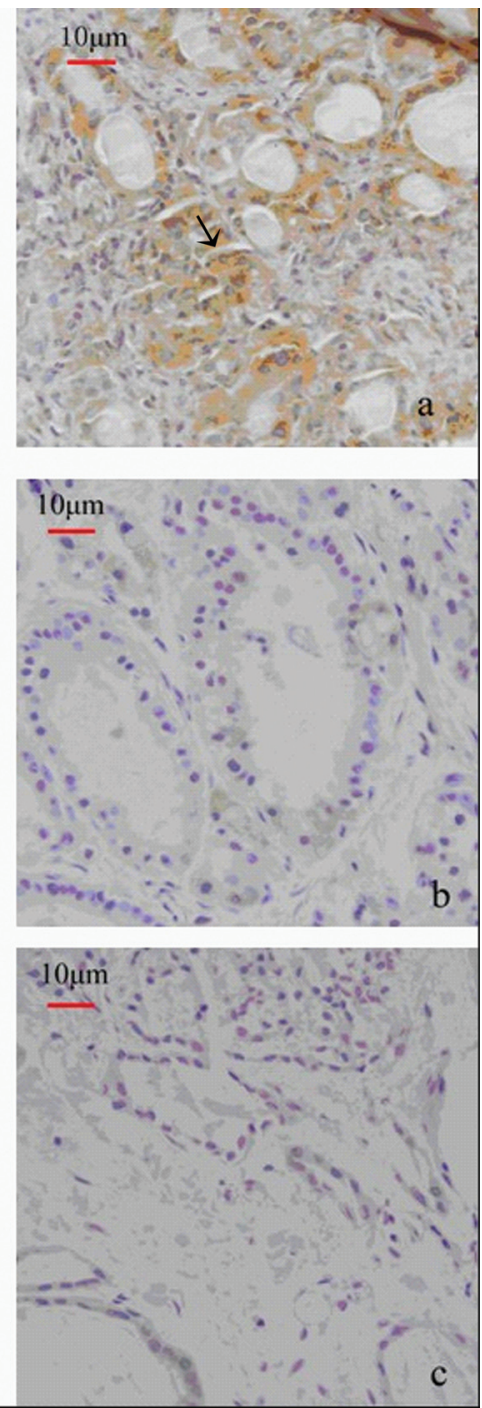

Figure 3. IL-17A and IL-23p19 in thyroid tissues revealed by immunohistochemistry. A, Thyroid gland section from Hashimoto's thyroiditis patients stained for IL-17A; a, section from Hashimoto's thyroiditis patients stained for IL-23p19. Arrows point to the inflammatory cells infiltrating in Hashimoto's thyroiditis tissues. $B$, Section from the Graves' disease patients stained for IL-17A; $b$, section from the Graves' disease patients stained for IL-23p19. C, Section from healthy controls stained for IL-17A; $c$, section from healthy controls stained for IL-23p19. unique pathologic feature of HT. In contrast, GD is characterized by the production of thyroid-stimulating antibodies and the proliferation of thyroid cells, as well as hyperthyroidism. Therefore, more investigations are required to probe the role of this newly identified T lymphocytes, Th17 cells, in e pathogenesis of AITD.

We found increased amounts of IL-17A in peripheral lymphocytes and the diseased tissues from HT patients, in agreement with a previous study, which also detected raised levels of Th17 cytokines in the peripheral blood and thyroid gland from AITD patients, mainly with HT (21). IL-17A is an inflammatory cytokine mainly secreted by Th17 cells and the causative role of Th17 cells has been proposed in many autoimmune diseases. For example, increased levels of IL-17 mRNA were detected both in cerebrospinal fluid and in peripheral blood in MS, and with the highest concentrations in blood during clinical exacerbations (22). As mentioned earlier, overexpression of IL-17 was examined in the synovium of patients with RA, but not in patients with osteoarthritis (9). In contrast to normal skin tissues, overexpression of IL-17, IL-23 and IL-6 was present in the skin lesions of psoriasis patients (19). Also, IL-17 expression in the mucosa and serum was more elevated in patients with inflammatory bowel diseases than in patients with infectious colitis, ischemic colitis or normal colonic mucosa (23). Based on these reports, both active and passive immunization targeting IL-17 showed efficiency in slowing progression to disease or reducing the score of disease severity in animal models of human RA and MS (24).

It is reasonable that intense staining for IL-17A should occur on the aggregation of lymphocytes. However, immunohistochemistry results have shown that thyroid epithelial cells (TEC) close to lymphocytes also had detectable expression. Previous studies have revealed that thyroid cells from AITD patients not only expressed MHC-II antigen but also produced many proinflammatory cytokines such as IL-1, IL-6, etc. Thus, the TEC not only acquired the power to present autoantigens to lymphocytes but was also able to destroy tissue indirectly (25). Therefore, we propose that a vicious cycle also exists between TEC and lymphocytes by producing IL-17A, leading to the progression of the chronic inflammation of HT. IL-23, which is produced by dendritic cells, drives naive $T$ cells to secrete IL-17 specifically and to help maintain or expand human Th17 cells. Our study also showed an elevated IL-23 expression in HT thyroid tissues, which corresponds 
to that of IL-17A. This finding provides indirect evidence that the IL-17/IL-23 axis plays an important role in the pathogenesis of $\mathrm{HT}$.

Since HT is one of the typical predominant Th1 diseases, we also investigated IFN-y expression. To our knowledge, the present study is the first to compare the expressions of Th1 and Th17 cell-related cytokines in patients with AITD. A study on an animal model of human $\mathrm{HT}$ observed increased numbers of Th1 and Th17 cells in the thyroid gland (26). Our study found overexpressed levels of IL-17A and IFN-Y mRNA both in lesioned tissues and in peripheral blood, but no difference in the expression of mRNA of these two cytokines in HT. These findings may suggest that there is no bias of Th1 or Th17 cells in HT. However, both cells may somehow participate synergistically in the process of HT. Regarding GD patients, no difference in IL-17A or IFN-Y expression was found between GD and control, indicating that Th17 and Th1 cells may play a lesser role in the development of the disease. This discrepant result may be due, at least in part, to the high levels of thyroid hormones. Previous studies had reported that circulating thyroid hormone levels seem to be related to the immune function in subjects with altered thyroid status (27). The high levels of thyroid hormones may

\section{References}

1. Teng W, Shan Z, Teng X, Guan H, Li Y, Teng D, et al. Effect of iodine intake on thyroid diseases in China. N Engl J Med 2006; 354: 2783-2793.

2. Karanikas G, Schuetz M, Wahl K, Paul M, Kontur S, Pietschmann P, et al. Relation of anti-TPO autoantibody titre and T-lymphocyte cytokine production patterns in Hashimoto's thyroiditis. Clin Endocrinol 2005; 63: 191-196.

3. Mazziotti G, Sorvillo F, Naclerio C, Farzati A, Cioffi M, Perna $\mathrm{R}$, et al. Type-1 response in peripheral CD4+ and CD8+ T cells from patients with Hashimoto's thyroiditis. Eur J Endocrinol 2003; 148: 383-388.

4. Fisfalen ME, Soltani K, Kaplan E, Palmer EM, van Seventer $\mathrm{GA}$, Straus $\mathrm{FH}$, et al. Evaluating the role of Th0 and Th1 clones in autoimmune thyroid disease by use of Hu-SCID chimeras. Clin Immunol Immunopathol 1997; 85: 253-264.

5. Tran EH, Prince EN, Owens T. IFN-gamma shapes immune invasion of the central nervous system via regulation of chemokines. J Immunol 2000; 164: 2759-2768.

6. McKenzie BS, Kastelein RA, Cua DJ. Understanding the IL-23-IL-17 immune pathway. Trends Immunol 2006; 27 : 17-23.

7. Yen D, Cheung J, Scheerens H, Poulet F, McClanahan T, McKenzie B, et al. IL-23 is essential for T cell-mediated colitis and promotes inflammation via IL-17 and IL-6. J Clin Invest 2006; 116: 1310-1316.

8. Cua DJ, Sherlock J, Chen Y, Murphy CA, Joyce B, Seymour $B$, et al. Interleukin-23 rather than interleukin-12 is the critical cytokine for autoimmune inflammation of the brain. Nature 2003; 421: 744-748.

9. Chabaud M, Durand JM, Buchs N, Fossiez F, Page G, Frappart L, et al. Human interleukin-17: A T cell-derived proin- up-regulate the humoral responses to counteract inflammation. This is consistent with the characteristics of these two subgroups of AITD, with the destruction of thyroid structure being more pronounced in HT than in GD. We have to admit that, because both Th1 and Th17 secrete several cytokines, IFN-y and IL-17A levels may not represent both Th cells completely. More specific cytokines should be investigated in further studies to confirm the relationship between Th1 and Th17 cells in HT pathogenesis or Th2 and Th17 cells in GD pathogenesis.

Our study confirmed the predominant role of Th17 cells in AITD pathogenesis. Our results also suggest a mixed response from Th17 and Th1 in HT, rather than one of them being dominant in the process of thyroid destruction. Our findings may help to elucidate the pathogenesis of AITD and to develop an immunospecific therapy.

\section{Acknowledgments}

We are very grateful to Professor Hong Ai, Ultrasound Department, and Professor Bingyin Shi, Endocrinology Department, for providing thyroid biopsy specimens. Research supported by the National Natural Science Foundation of China (\#30871185 and \#81070627). flammatory cytokine produced by the rheumatoid synovium. Arthritis Rheum 1999; 42: 963-970.

10. Kocjan T, Wraber B, Repnik U, Hojker S. Changes in Th1/ Th2 cytokine balance in Graves' disease. Pflugers Arch 2000; 440: R94-R95.

11. Miyauchi S, Matsuura B, Onji M. Increased levels of serum interleukin-18 in Graves' disease. Thyroid 2000; 10: 815-819.

12. Okumura M, Hidaka Y, Matsuzuka F, Takeoka K, Tada H, Kuma K, et al. CD30 expression and interleukin-4 and interferon-gamma production of intrathyroidal lymphocytes in Graves' disease. Thyroid 1999; 9: 333-339.

13. Bettelli E, Korn T, Kuchroo VK. Th17: the third member of the effector T cell trilogy. Curr Opin Immunol 2007; 19: 652657.

14. Li Y, Chu N, Hu A, Gran B, Rostami A, Zhang GX. Increased IL-23p19 expression in multiple sclerosis lesions and its induction in microglia. Brain 2007; 130: 490-501.

15. Kim HR, Cho ML, Kim KW, Juhn JY, Hwang SY, Yoon CH, et al. Up-regulation of IL-23p19 expression in rheumatoid arthritis synovial fibroblasts by IL-17 through PI3-kinase-, NF-kappaB-and p38 MAPK-dependent signalling pathways. Rheumatology 2007; 46: 57-64.

16. Hwang SY, Kim HY. Expression of IL-17 homologs and their receptors in the synovial cells of rheumatoid arthritis patients. Mol Cells 2005; 19: 180-184.

17. Schmidt C, Giese T, Ludwig B, Mueller-Molaian I, Marth T, Zeuzem S, et al. Expression of interleukin-12-related cytokine transcripts in inflammatory bowel disease: elevated interleukin-23p19 and interleukin-27p28 in Crohn's disease but not in ulcerative colitis. Inflamm Bowel Dis 2005; 11: 16-23.

18. Wong CK, Ho CY, Li EK, Lam CW. Elevation of proinflam- 
matory cytokine (IL-18, IL-17, IL-12) and Th2 cytokine (IL-4) concentrations in patients with systemic lupus erythematosus. Lupus 2000; 9: 589-593.

19. Li J, Chen X, Liu Z, Yue Q, Liu H. Expression of Th17 cytokines in skin lesions of patients with psoriasis. $J$ Huazhong Univ Sci Technolog Med Sci 2007; 27: 330-332.

20. Maierhaba M, Zhang JA, Yu ZY, Wang Y, Xiao WX, Quan $Y$, et al. Association of the thyroglobulin gene polymorphism with autoimmune thyroid disease in Chinese population. Endocrine 2008; 33: 294-299.

21. Figueroa-Vega N, Alfonso-Pérez M, Benedicto I, SánchezMadrid F, González-Amaro R, Marazuela M. Increased circulating pro-inflammatory cytokines and Th17 lymphocytes in Hashimoto's thyroiditis. J Clin Endocrinol Metab 2010; 95: 953-962.

22. Matusevicius D, Kivisäkk P, He B, Kostulas N, Ozenci V, Fredrikson $\mathrm{S}$, et al. Interleukin-17 mRNA expression in blood and CSF mononuclear cells is augmented in multiple sclerosis. Mult Scler 1999; 5: 101-104.

23. Fujino S, Andoh A, Bamba S, Ogawa A, Hata K, Araki Y, et al. Increased expression of interleukin 17 in inflammatory bowel disease. Gut 2003; 52: 65-70.

24. Röhn TA, Jennings GT, Hernandez M, Grest P, Beck M, Zou $\mathrm{Y}$, et al. Vaccination against IL-17 suppresses autoimmune arthritis and encephalomyelitis. Eur J Immunol 2006; 36: 2857-2867.

25. Todd I, Pujol-Borrell R, Hammond LJ, Bottazzo GF, Feldmann M. Interferon-gamma induces HLA-DR expression by thyroid epithelium. Clin Exp Immunol 1985; 61: 265-273.

26. Horie I, Abiru N, Nagayama Y, Kuriya G, Saitoh O, Ichikawa $\mathrm{T}$, et al. T helper type 17 immune response plays an indispensable role for development of iodine-induced autoimmune thyroiditis in nonobese diabetic- $\mathrm{H} 2 \mathrm{~h} 4$ mice. Endocrinology 2009; 150: 5135-5142.

27. Yen PM. Physiological and molecular basis of thyroid hormone action. Physiol Rev 2001; 81: 1097-1142. 